\title{
Innovation design of medical equipment based on TRIZ
}

\author{
Changqing $\mathrm{Gao}^{\mathrm{a}, *}$, Leiming Guo ${ }^{\mathrm{b}}$, Fenglan $\mathrm{Gao}^{\mathrm{c}}$ and Bo Yang ${ }^{\mathrm{a}}$ \\ ${ }^{a}$ School of Mechanical Engineering, University of Jinan, Jinan, Shandong, China \\ ${ }^{\mathrm{b}}$ Department of Pediatrics, Shandong Provincial Hospital, Jinan, Shandong, China \\ 'Department of Kidney, Binzhou People's Hospital, Binzhou, Shandong, China
}

\begin{abstract}
.
BACKGROUND: Medical equipment is closely related to personal health and safety, and this can be of concern to the equipment user. Furthermore, there is much competition among medical equipment manufacturers. Innovative design is the key to success for those enterprises.

OBJECTIVE: The design of medical equipment usually covers vastly different domains of knowledge. The application of modern design methodology in medical equipment and technology invention is an urgent requirement.

METHODS: TRIZ (Russian abbreviation of what can be translated as 'theory of inventive problem solving') was born in Russia, which contain some problem-solving methods developed by patent analysis around the world, including Conflict Matrix, Substance Field Analysis, Standard Solution, Effects, etc. TRIZ is an inventive methodology for problems solving.

RESULTS: As an Engineering example, infusion system is analyzed and re-designed by TRIZ. The innovative idea is generated to liberate the caretaker from the infusion bag watching out. The research in this paper shows the process of the application of TRIZ in medical device inventions.

CONCLUSION: It is proved that TRIZ is an inventive methodology for problems solving and can be used widely in medical device development.
\end{abstract}

Keywords: Innovation design, TRIZ, medical equipment

\section{Introduction}

With the development of society, more and more attentions are paid to the medical equipments or devices that have much help to improve people's life quality. However, most Chinese medical equipment manufacturing enterprises lack the innovation design ability. The market of the advanced medical equipments is controlled mainly by several international medical equipment enterprises, such as GE, SIEMENS and PHILIPS.

More and more medical equipment enterprises recognize the importance of the application of the modern design methodology in technology innovation and new product development, which include Ergonomics [1], emotional design [2], Cognitive Psychology [3], etc. TRIZ [4] is a powerful method for inventive ideas generation, which has been used successfully in mechanical product design [5]6], chemistry industry [7], bionics [8] and other domains. Gradually, the application of TRIZ in medical equipment design process grasp the researcher's attention [10]. The Computer Aided Innovation technology based on TRIZ can help the conceptual design for the new product.

\footnotetext{
${ }^{*}$ Corresponding author: Changqing Gao, School of Mechanical Engineering, University of Jinan, No. 336 Nanxinzhuang West Road, Jinan, Shandong, China. Tel.: +86 15689698658; Fax: +86 05318715 4048; E-mail: me_gaocq@ujn.edu.cn. 
Table 1

Database of effects

\begin{tabular}{|c|c|c|}
\hline No. & Standard functions & Effects \\
\hline 1 & Measure temperature & $\begin{array}{l}\text { Thermal expansion } \\
\text { Thermal-electrical law } \\
\text { Radiation spectrum } \\
\text { Curie point } \\
\text { Resistance }\end{array}$ \\
\hline 2 & Reduce temperature & $\begin{array}{l}\text { Phase transitions } \\
\text { Thomson effects } \\
\text { Thermal-electrical law } \\
\text { Magnetic calorie effect } \\
\text {... }\end{array}$ \\
\hline$\cdots$ & $\ldots$ & $\ldots$ \\
\hline 19 & Change a dimension & $\begin{array}{l}\text { Thermal expansion } \\
\text { Deformation } \\
\text { Piezoelectric effect } \\
\ldots\end{array}$ \\
\hline$\cdots$ & $\ldots$ & $\cdots$ \\
\hline 30 & $\begin{array}{l}\text { Initiate (intensify) } \\
\text { chemical reactions }\end{array}$ & $\ldots$ \\
\hline
\end{tabular}

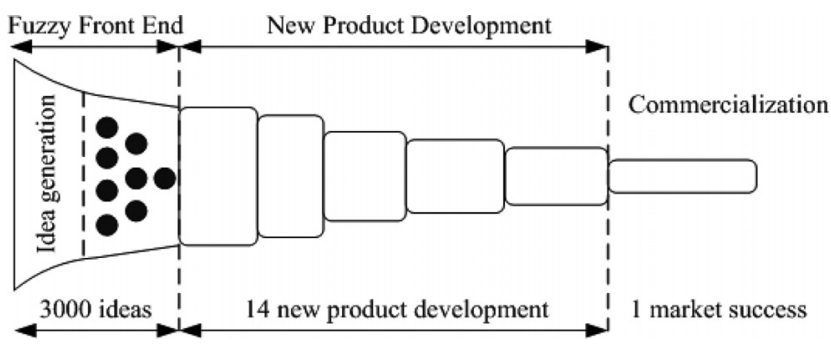

Fig. 1. The process of innovation.

\begin{tabular}{|c|c|c|c|c|c|c|c|c|}
\hline \multirow{2}{*}{\multicolumn{2}{|c|}{$\begin{array}{l}\text { Degraded } \\
\text { parameter } \\
\text { be improved }\end{array}$}} & 1 & 2 & $\ldots$ & 9 & 10 & $\ldots$ & 39 \\
\hline & & $\cdots$ & $\cdots$ & $\cdots$ & $\begin{array}{l}\text { ¿ूँ } \\
\text { के }\end{array}$ & : & $\ldots$ & $\ldots$ \\
\hline 1 & $\begin{array}{c}\text { Weight of } \\
\text { moving object }\end{array}$ & & & & $\begin{array}{c}2,8, \\
15,38\end{array}$ & $\begin{array}{c}8,10 \\
18,37\end{array}$ & & $\begin{array}{r}35,3 \\
24,37\end{array}$ \\
\hline 2 & $\begin{array}{c}\text { Weight of } \\
\text { stationary object }\end{array}$ & - & & & - & $\begin{array}{l}8,10 \\
19,35\end{array}$ & & $\begin{array}{r}1,28 \\
15,35\end{array}$ \\
\hline$\cdots$ & & & & & & & & \\
\hline 39 & Productivity & $\begin{array}{l}35,26 \\
24,37\end{array}$ & $\begin{array}{l}28,27 \\
15,3\end{array}$ & & - & $\begin{array}{l}28,15 \\
10,36\end{array}$ & & \\
\hline
\end{tabular}

Fig. 2. Conflict matrix.

\section{Process of innovation}

The process of innovation [11] can be shown in Fig. 1, which includes three sub-processes: fuzzy front end, new product development and commercialization. According to the Fig. 1, of 3000 ideas generated in fuzzy front end, about 14 new product development projects are initiated. Moreover there is only one successful product idea can survive up to market launch [11].

During the process of innovation, problems can appear anytime in fuzzy front end, new product development and commercialization. There are two kinds of problem type. One is the routine problem, which means all critical steps to a solution are known. The other is called inventive problem, for which at least one essential step to a solution is unknown [12].

Resolving the problems appear in the process of innovation is the key to innovation design of the product.

\section{TRIZ}

According to reference [12], theory of inventive problem solving (TRIZ) is defined as a humanoriented knowledge-based systematic methodology of inventive problem-solving. TRIZ began in 1946 in Russia, which includes systematic steps including problem definition, function analysis, and some tools for problem-solving. Conflict Matrix, Effect, Substance-field analysis, Trimming and Evolution route are the typical inventive problem-solving tools in TRIZ. Those concepts are discussed in details in this paper below. 
Table 2

Category of 76 standard solutions

\begin{tabular}{clc}
\hline Category & Standard solutions & Amount \\
\hline 1 & $\begin{array}{l}\text { Construction and destruction of } \\
\text { substance-field systems }\end{array}$ & 13 \\
2 & $\begin{array}{l}\text { Development of substance-field } \\
\text { systems }\end{array}$ & 23 \\
3 & $\begin{array}{l}\text { Transition to super-system and to } \\
\text { micro level }\end{array}$ & 6 \\
4 & $\begin{array}{l}\text { Standards for system detection and } \\
\text { measurement }\end{array}$ & 17 \\
5 & Standards for using standards & 17 \\
\hline
\end{tabular}

Table 3

Evolution routes

\begin{tabular}{cl}
\hline Category & Evolution routes \\
\hline 1 & Increasing degree of ideality \\
2 & Non-uniform evolution of sub-systems \\
3 & Transition to a higher level system \\
4 & Increasing dynamism \\
5 & Transition to micro level \\
6 & Completeness \\
7 & Shortening of energy flow path \\
8 & Increasing substance-field interactions \\
9 & Harmonization of rhythms \\
\hline
\end{tabular}

\subsection{Conflict matrix}

Where there is an unexpected problem in a technical system, there is a conflict. The classification of it involves technical conflict and physical conflict.

When improving one parameter of a system causes another parameter to deteriorate, technical conflict appears. 40 Inventive principles are the repeatedly rules discovered by patent analysis for technical conflict resolving. Technical conflict can be described by 39 engineering parameters uniformly [13].

Conflict matrix is shown in Fig. 2, which is a table including information of 39 engineering parameters describing technical conflict and 40 inventive principles for technical conflict resolving.

\subsection{Effect}

Function describing or modeling is a base in new product development or redesign process. TRIZ uses a suite of 30 standard functions describing the typical mechanical design functional requirements during the invention process.

According to Systematic Approach of Pahl and Beitz (SAPB), the functions (or sub-functions) are usually fulfilled by some process including physical, chemical or biological ones. A process realized by the corresponding effects and the determined geometric and material characteristics. Effects are usually the powerful knowledge for locating a solution for a function target.

In order to simply the effects application, the Effect database is built on the mapping relationship of function and effect. There is a mapping link between a function and the corresponding list of effects that can employed to realize the function [12]. The relationship of standard functions and effects can be shown in Table 1.

\subsection{Standard solutions}

In the viewpoint of TRIZ, a function can be achieved when a substance acts on the other one by a field, usually a type of energy. Tool is the executor of the action and Object is the subject of the action. Sometimes, a substance is both Tool and Object. Substance-Field Analysis is a process of modeling problems and analyzing the components of a technical system with the steps mentioned above.

Standard solutions are accomplished by Altshuller and his colleagues from 1975 to 1985. There are 76 Standard solutions in TRIZ methodology. They are the method based on Substance-Field Analysis to illustrate the standard conditions and criteria for problems solving by reconstructing the substance and field. The category of 76 Standard solutions is listed in Table 2 mentioned below [14]. 


\begin{tabular}{|c|c|c|}
\hline Rules & Process & Contents \\
\hline A & $\begin{array}{c}\text { Function } \\
\text { Carrier }\end{array} \stackrel{\begin{array}{l}\text { Object of the } \\
\text { Function }\end{array}}{\text { Action }}$ & $\begin{array}{l}\text { Function Carrier can be trimmed if } \\
\text { the object of the function is trimmed. }\end{array}$ \\
\hline B & $\left.\begin{array}{c}\text { Function } \\
\text { Carrier }\end{array}\right)$ & $\begin{array}{l}\text { Function Carrier can be trimmed if } \\
\text { the object of the function can } \\
\text { perform the useful function by itself. }\end{array}$ \\
\hline $\mathrm{C}$ & $\begin{array}{l}\text { Function } \\
\text { Carrier 1 } \\
\text { Function } \\
\text { Carrier 2 }\end{array}$ & $\begin{array}{l}\text { Function Carrier can be trimmed if } \\
\text { another Function Carrier can } \\
\text { perform its the useful function. }\end{array}$ \\
\hline
\end{tabular}

Fig. 3. Trimming rules.

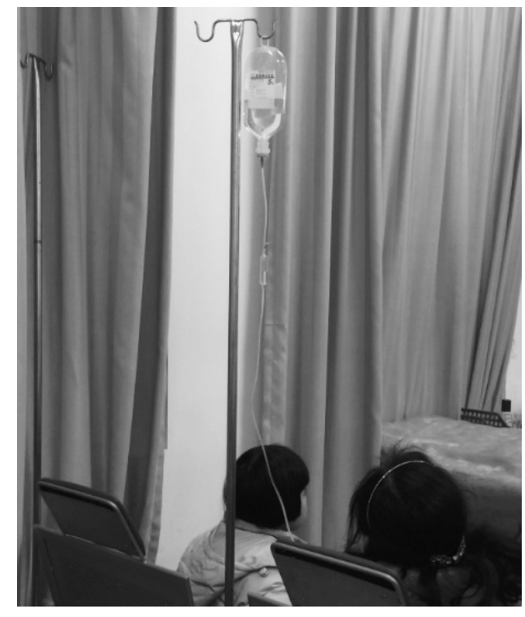

Fig. 4. Patient with infusion.

\subsection{Trimming}

Trimming is a method that means eliminating one or more components of the technical system and redistributing their useful functions among the remaining components in the system or super-system. Three rules for trimming components are introduced in Fig. 3.

\subsection{Evolution route}

Patent analysis shows that the evolution process of an engineering system is ruled by some certain patterns, which are called Evolution routes based on thousands of patents and improvement of thousands of products and technologies.

According to the Evolution routes, the S-curve of any product has a typical life cycle of pregnancy, birth, childhood, adolescence, maturity and decline.

The typical patterns of Evolution routes for the engineering system are listed in Table 3 [14].

\subsection{General process of TRIZ tools using}

Where a challenge appears in a technical system, problem analysis starts with doing another thing in order to identify the classification of the problem. TRIZ provides some tool for the corresponding invention problems, such as Conflict, Effect, and Standard problem, etc. When the classification of problem has been identified, the corresponding tools can be applied to generate an idea for the problem solving by analog thinking with the help of knowledge base drawn from the patent analysis around the world. Sometimes, the process mentioned above should repeat several turns.

\section{Computer aided innovation tool}

Innovation Engine (Version 2.0) is a CAI system based on TRIZ and knowledge representation methods with Microsoft visual basic 2012 and Microsoft Office Access 2007 in Windows 8 operation system, which is developed by Institute of TRIZ in University of Jinan. 


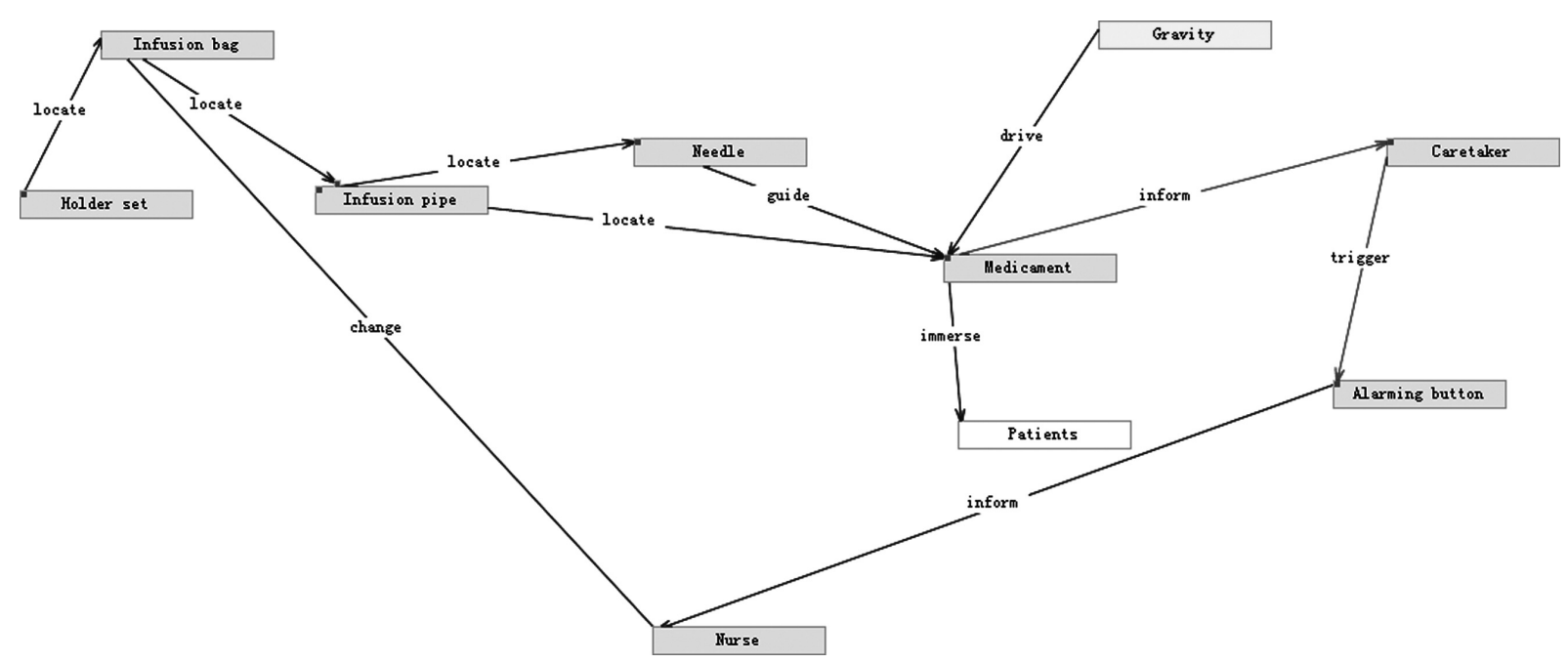

Fig. 5. Function analysis for the technical system.

Innovation Engine includes some function modules, such as Project Navigation, Problem Describing, Conflicts, Effects, and Standard Solutions, etc. Project Navigation provides some illustrations for the operations of this CAI system. Problem Describing is a model for the target problem describtions. Conflicts, Effects, Standard Solutions and others are various sections for problem-solving according to TRIZ process. Knowledge information is stored in some MDB files. The users can retrieve the corresponding inventive information that is needed to help them for ideas generation.

\section{Case study}

This section discusses the application of TRIZ in technology innovation of medical device.

\subsection{Problem description}

Infusion is a standard treatment for the patients. If the patient is with worse health condition, the caretaker is usually needed for disease treatment to promise the patient a full rest. As shown in Fig. 4, if there are more than one infusion bag, an important work for caretaker is to inform the nurse in time to change the corresponding infusion bag. In most hospitals, there is an informing button near the patient that can give an alarming to the nurse station. Even in this situation, caretaker should observe the infusion bag carefully to know the process of the injection. In fact, caretaker has many works to do for patient caring. Watching out the process of the infusion is not the only job for him or her. However it takes the caretaker so much energy and attention. How to liberate the caretaker from the infusion bag watching out is a need for both patient and caretaker.

\subsection{Process of problem-solving}

According to the situation description, function analysis for the technical system is the first job to do for problem-solving. The main components of the technical system include infusion bag, holder set, infusion pipe, needle, medicament, patients, nurse, gravity, caretaker, alarming button, and patient. The 


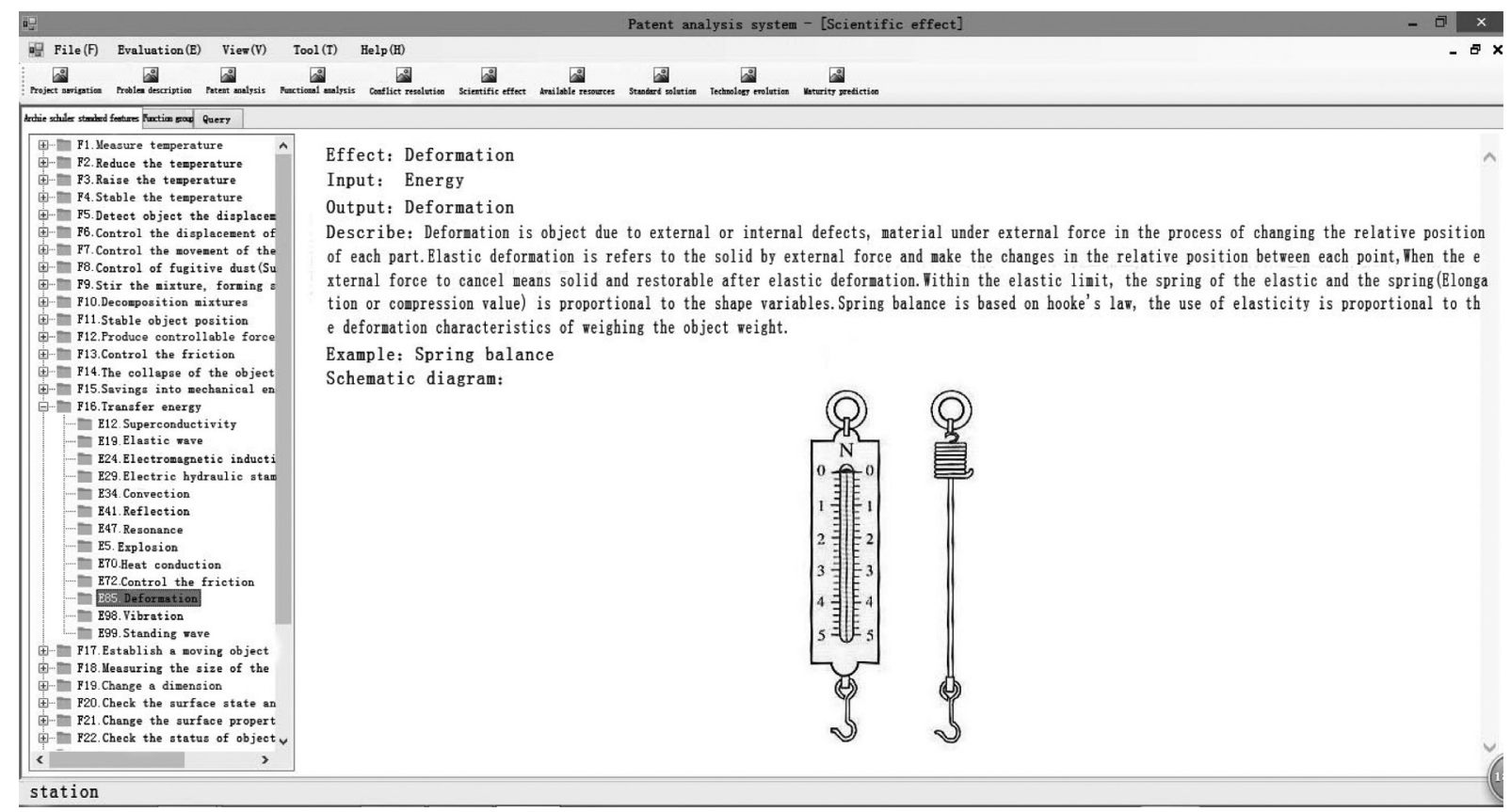

Fig. 6. Effects for standard function.

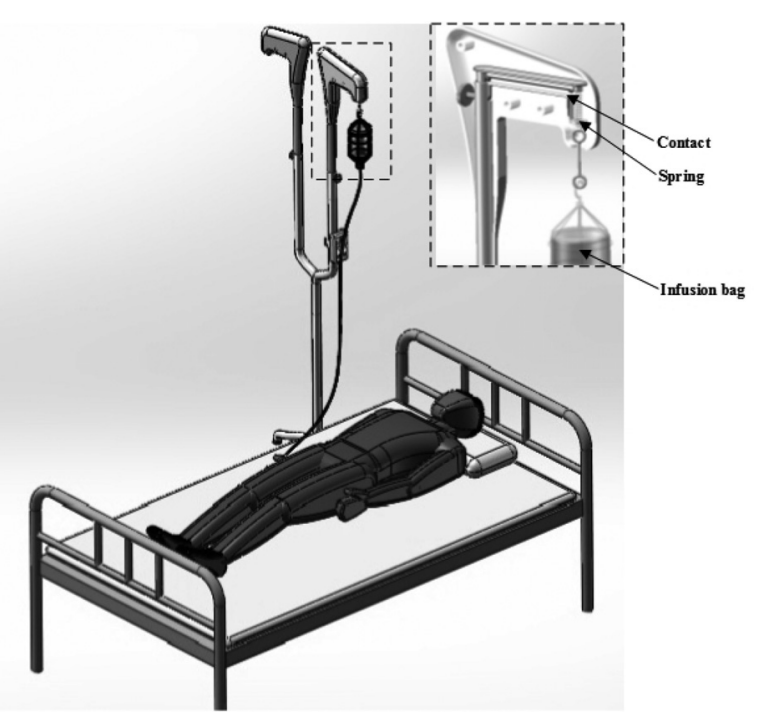

Fig. 7. Design project of automation alarming system for infusion.

action between two components is shown in Fig. 5. The function analysis is done by function model of Innovation Engine.

In this situation, liberating the caretaker from the infusion bag watching out is a problem. If the caretaker does not be needed to press the alarming button, then the problem can be solved. This is a typical trimming problem in TRIZ. According to trimming rules in Fig. 3, Rule C can be applied. If 'press', which is the function of caretaker, can be performed by another function carrier, the caretaker 
can be liberated from this job. So how to realize the 'press' function is the sub-problem for the next step.

Effect is another powerful tool in TRIZ for the locating a solution for a function target. There are 30 standard functions in TRIZ for inventive problem-solving. 'Press Alarming button' is an action with a force usage. And the mechanical force is a kind of energy field. So this action is related to the F12 and F16 standard functions. F12 means to produce controllable force, high pressure. F16 means to transfer energy. The information can be retrieved within the corresponding folders. There is no suitable effect knowledge for us within the F12 folder. The F16 folder can be the next folder for information retrieved. The corresponding effect knowledge can be retrieved by Effect Model of Innovation Engine. 'Deformation' is a method for 'Transfer energy'. According to Hooke's law, within the elastic limit of a solid material, the deformation produced by a force is proportional to the force. Spring balance is a case for detecting a force by deformation. As shown in Fig. 6.

An innovation idea can be generated based on spring balance, in which a spring is used to link the infusion bag and alarming contact, as shown in Fig. 7. When the medicament in the infusion bag becomes less and less, the length of spring becomes shorter and shorter. There exists a point where the contacts can touch together. Then alarming function can be performed.

\section{Conclusions}

Innovation design of medical equipment content many different subjects domain. TRIZ is a methodology for technical innovation that is built on the analysis of various domain patents in the world. TRIZ provides many tools for inventive problem-solving including Conflict Matrix, Effect, Trimming, Standard solutions, etc. The innovation idea can be generated by the systematic approach based on those inventive problem-solving tools. The application of TRIZ in medical equipment design process becomes a research hotspot in medical equipment design and innovation methodology research.

\section{Acknowledgements}

This work was financially supported by Science and Technology Development Plan Project of Shandong Province (2014GGX106003), Large Equipment Upgrade Project of Shandong Province (2012SJGZ15).

\section{References}

[1] T. Rui, Research on ergonomics of medical equipment, Master Degree Dissertation, Zhejiang University, 2008.

[2] L. Haiyan, L. Jiuxi, Emotional design of medical appliance, Information of Chinese Medical Equipment, 12(11), (2006), 19-21.

[3] L. ZhiBin, W. Xuan, The centrifuge product modeling design research based on the brand situation, Development and Innovation of Machinery and Electrical Products, 26(1), (2013), 63-64.

[4] G. Altshuller, The innovation algorithm, Technical Innovation Center, Inc, Worcester, 2000, 1-10.

[5] G. Changqing, Ch. Wei, M. Shanmin, Y. Bo, Research on methodology of technology forecasting based on TRIZ, Journal of Machine Design, 31(8), (2014), 1-4.

[6] L. Miao, M. Xinguo, H. Lina, Zh. Maokuan, X. Zhitao, A TRIZ-based trimming method for patent design around, Computer-Aided Design 62, (2015), 20-30.

[7] R. Srinivasan, A. Kraslawski, Application of the TRIZ creativity enhancement approach to design of inherently safer chemical processes, Chemical Engineering and Processing, 45(6), (2006), 507-514. 
[8] X. Yong, Flow field structure design based on bionics and TRIZ for PEMFC bipolar plate, Master Degree Dissertation, Wuhan University of Technology, 2012.

[9] S.M. Cretu, Creativity in bionics, Journal of TRIZ in Engineering Design, 1(1), (2005), 14-26.

[10] P. Lei, Innovative models of medical equipment eesign based on ontology theory and TRIZ theory, Master Degree Dissertation, Dalian Jiaotong University, 2013.

[11] R. Tan, A sequential process model for idea generation in fuzzy front end using TRIZ, Journal of TRIZ in Engineering Design, 2(1), (2006), 59-73.

[12] S.D. Savransky, Engineering of creativity, CRC Press, Florida, 2000, pp. 1-23.

[13] T. John, Step-by-step QFD: Customer-driven product design, St. Lucie Press, Florida, 2000, pp. 127-139.

[14] F. Victor, R. Eugene, Innovation on demand, Cambridge University Press, Cambridge, 2007, pp. 47-78. 